\title{
A Threshold Model of Gold Price Market on the Two Stock Markets: Study of the Taiwan and the Korea Markets
}

\author{
Wann-Jyi Horng ${ }^{1}$, Jui-Chen Chang ${ }^{2}$ \\ ${ }^{1}$ Department of Hospital and Health Care Administration, Chia Nan University of Pharmacy \& Science, Tainan 71710, Taiwan \\ ${ }^{2}$ Department of Finance \&Institute of Financial Management, Nanhua University, Chia-Yi 622, Taiwan \\ hwj7902@mail.chna.edu.tw
}

\begin{abstract}
Under the factor of gold price market, the empirical results show that the dynamic conditional correlation (DCC) and the bivariate asymmetric $\operatorname{IGARCH}(1,1)$ model is appropriate in evaluating the relationship of the Taiwan's and the Korea's stock markets. The empirical result also indicates that the Taiwan's and the Korea's stock markets is a positive relation. The average estimation value of correlation coefficient equals to 0.7207 , which implies that the two stock markets is synchronized influence. Based on the threshold of gold price volatility, the empirical result also shows that the Taiwan's and the Korea's stock markets do have an asymmetrical effect. And the variation risk of the Taiwan's and Korea's stock market returns receives the influence of the gold market. Besides, under the good news, the error square item of the Taiwan's stock market affects the variation risk of the Korea's stock market. And the error square item of the Korea's stock market affects the variation risk of the Taiwan's stock market.

Index Terms - stock market returns, gold price, asymmetric effect, error square item, bivariate asymmetric IGARCH model
\end{abstract}

\section{I . Introduction}

In recent years, South Korea's economy was the fast growth, for example, the stock market index rose 3.99\% in 2006, and the stock market index has risen $6.98 \%$ in 2007 (Data source: Bloomberg, 2007/1/1 2007/4/18). Besides, in 2009, the foreign exchange reserve of South Korea is fifth big in the world. We also know that South Korea's economical physique belongs to half island economy, and close trade ties with Taiwan. We also know that Taiwan is an important economic and trade area in Asia. Taiwan undoubtedly also plays a very important role in the global economic and financial system. When the investor has an investment in the international stock market, he/she will usually care about the international capital the motion situation, the international politics and the economical situation change, in particular, in the Taiwan and the Korea stock market change. There is a close relationship for the geographic position based on the trade and the circulation of capital with the Taiwan and the Korea, but the Taiwan and Korea may also receive the influence of national gold price market. Therefore, the relation between the Taiwan's and the Korea's stock markets with a factor of the gold market is worth further discussion.

The purpose of the present paper is to examine the relations of the Taiwan's and the Korea's stock markets with a factor of gold price market. This paper also further discusses the affect of the gold market for the Taiwan and the Korea stock market returns. This paper is also used the volatility value of gold price return as the threshold. Besides, we also further consider the error square item of the Taiwan's stock market whether affects the variation risk of the Korea's stock market. The error square item of the Korea's stock market whether affects the variation risk of the Taiwan's stock market. The organization of this paper is as follows: Section 2 descibes the data characteristics; Section 3 introduces the asymmetric test of the DCC and the bivariate $\operatorname{IGARCH}(1,1)$; Section 4 presents the proposed model and the empirical results, and finally Section 5 summarizes the conclusions of this study.

\section{Data characteristics}

\section{A . Data Sources}

The data of this research included the stock price of Taiwan, the stock price of Korea and the gold price are collected between January, 2007 and August, 2010. The source of the stock data was the Taiwan economic Journal (TEJ), a database in Taiwan. The Taiwan stock price refers to the Taiwan stock price index, the Korea stock price refers to the Korea stock price index, and the gold price refers to KITCO gold market, a database in London. During the process of data analysis, in case that there was no stock market price available on the side of the Taiwan's and the Korea's stock markets or on the side of the gold market due to holidays, the identical time stock price data from one side was deleted. After this, the three variables samples are 859 .

\section{B . Basis Statistics and Trend Charts}

To compute the return of the Taiwan stock market adopts the natural logarithm difference, rides 100 again. The return of the Korea stock market also adopts the natural logarithm difference, rides 100 again. The return of the gold price also adopts the natural logarithm difference, rides 100 again. In Figure 1, the Taiwan, the Korea and the gold price return rates' volatility shows the clustering phenomenon, so that we may know the Taiwan stock market, the Korea stock market and the gold price market have certain relevance.

Table 1 presents the three sequences kurtosis coefficients are all bigger than 3 , which this result implies that the normal distribution test of Jarque-Bera is not normal distribution. Therefore, the heavy tails distribution is used in this paper. 

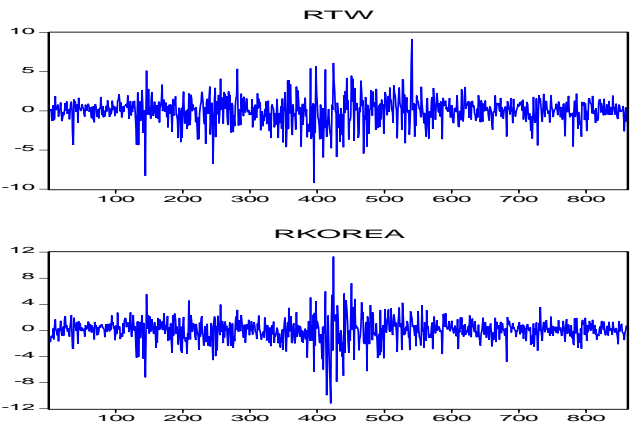

RaOp

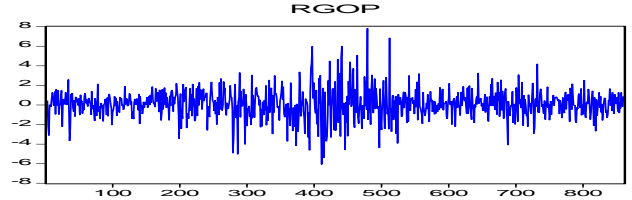

Fig.1 Tend charts of Taiwan's, Korea's and gold market return rates,

Table 1 Data Statistics

\begin{tabular}{|l|l|l|l|}
\hline Statistics & RTW & RKOREA & RGOP \\
\hline Mean & -0.004569 & 0.022625 & 0.077694 \\
\hline S-D & 1.714660 & 1.789549 & 1.470043 \\
\hline Skewed & -0.357950 & -0.554969 & 0.122967 \\
\hline Kurtosis & 6.560649 & 9.328589 & 6.010126 \\
\hline J-B N & $471.569^{* * * *}$ & $1475.867^{* * * *}$ & $326.088^{* * * *}$ \\
(p-value) & $(0.0000)$ & $(0.0000)$ & $(0.0000)$ \\
\hline sample & 858 & 858 & 858 \\
\hline
\end{tabular}

Notes: (1) J-B N is the normal distribution test of Jarque-Bera.

(2) S-D is denoted the standard deviation

(3) ${ }^{* * *}$ denote significance at the level $1 \%$.

\section{Unit Root and Co-integration Tests}

This paper further uses the unit root tests of ADF (Dickey and Fuller ${ }^{3}$ ) and KSS (Kapetanios et al ${ }^{13}$ ) to determine the stability of the time series data. The ADF and KSS examination results is listed in Table 2. It shows that Taiwan's, the Korea's and the gold's return rates do not have the unit root characteristic- namely, the three markets are stationary time series data, under $\alpha=1 \%$ significance level.

Table 2 Unit Root Test of ADF and KSS for the Return Data

\begin{tabular}{|l|l|l|l|}
\hline ADF & RTW & RKOREA & RGOP \\
\hline Statistic & $-5.551^{* * *}$ & $-28.567^{* * *}$ & $-28.716^{* * *}$ \\
\hline Critical value & -3.969 & -3.415 & -3.130 \\
\hline (Significant level) & $(\alpha=1 \%)$ & $(\alpha=5 \%)$ & $(\alpha=10 \%)$ \\
\hline KSS & RTW & RKOREA & RGOP \\
\hline Statistic & $-14.050^{* * * *}$ & $-13.279^{* * * *}$ & $-15.792^{* * * *}$ \\
\hline Critical value & -2.820 & -2.220 & -1.920 \\
\hline (Significant level) & $(\alpha=1 \%)$ & $(\alpha=5 \%)$ & $(\alpha=10 \%)$ \\
\hline
\end{tabular}

Notes: ${ }^{* * *}$ denote significance at the level $1 \%$.

Using Johansen's ${ }^{9}$ co-integration test as illustrated in Table 3 at the significance level of $0.05(\alpha=5 \%)$ does not reveal of $\lambda_{\max }$ and Trace statistics. This indicated that the Taiwan stock market, the Korea stock market and the gold price market do not have a co-integration relation. Therefore, we do need to consider the model of error correction.

Table 3 Co-Integration Test ( Var Lag=1)

\begin{tabular}{|l|l|l|}
\hline$H_{0}$ & $\lambda_{\max }$ & Critical value \\
\hline None & 20.0589 & 25.8232 \\
\hline At most 1 & 13.3793 & 19.3870 \\
\hline At most 2 & 2.3077 & 12.5180 \\
\hline$H_{0}$ & Trace & Critical value \\
\hline None & 35.7458 & 42.9153 \\
\hline At most 1 & 15.6870 & 25.8721 \\
\hline At most 2 & 2.3077 & 12.5180 \\
\hline
\end{tabular}

Notes: The lag of VAR is selected by the BIC rule (Schwarz ${ }^{1}$ ). The critical value is given under the level $5 \%$.

\section{ARCH Effect Test}

Based on the formula (1) and (2) as below, we uses the methods of LM test $\left(\right.$ Engle $\left.^{4}\right)$ and F test $\left(\right.$ Tsay $\left.^{11}\right)$ to test the conditionally heteroskedasticity phenomenon. In Table 4, the results of the ARCH effect test show that the two markets have the conditionally heteroskedasticity phenomenon exists. This result suggests that we can use the GARCH model to match and analyze it.

Table 4 ARCH Effect Test

\begin{tabular}{|l|l|l|}
\hline RTW & Engle LM test & Tsay F test \\
\hline Statistic & $205.928^{* * * *}$ & $3.4392^{* * * *}$ \\
\hline (p-value) & $(0.0000)$ & $(0.0000)$ \\
\hline RKOREA & Engle LM test & Tsay F test \\
\hline Statistic & $343.642^{* * *}$ & $14.1969^{* * *}$ \\
\hline (p-value) & $(0.0000)$ & $(0.0000)$ \\
\hline
\end{tabular}

Notes: ${ }^{* * *}$ denote significance at the level $1 \%$.

\section{Asymmetric test of the bivariate igarch model}

The DCC and the bivariate $\operatorname{IGARCH}(1,1)$ model with a factor of gold market can be constructed in this paper, the details are omitted. The asymmetric test methods (Engle and $\mathrm{Ng}^{5}$ ) are used the following two methods as: positive size bias test and joint test. By the joint test shows that the Taiwan's and the Korea's stock price markets do have the asymmetry effects in Table 5.

Table 5 Asymmetric Test of the DCC and the Bivariate-IGARCH(1, 1)

\begin{tabular}{|l|l|l|}
\hline RTW & Positive size bias test & Joint test \\
\hline F statistic & 0.3683 & 2.4309 \\
\hline (p-value) & $(0.5441)$ & $(0.0639)$ \\
\hline RKOREA & Positive size bias test & Joint test \\
\hline F statistic & 0.5950 & 4.4642 \\
(p-value) & $(0.4407)$ & $(0.0040)$ \\
\hline
\end{tabular}

Notes: p-value $<\alpha$ denote significance. ( $\alpha=1 \%, \alpha=5 \%$ ). 


\section{Proposed Model And Empirical Results}

Based on the results of the asymmetric test, and gold market will also affect the Taiwan's and the Korea's stock markets, we follows the idea of GARCH model (Bollerslev ${ }^{14}$ ), the ideas of Hammoudeh et $\mathrm{al}^{7-8}$, the ideas of Engle ${ }^{6}$ and Tse and Tusi ${ }^{12}$. This idea of GARCH model can also refer the book of Tsay ${ }^{11}$. After model process selection, in this paper, we may use the DCC and the bivariate asymmetric IGARCH $(1,1)$ model to construct the relationships of the Taiwan and the Korea stock market returns, the proposed model is illustrated as follows:

$$
\begin{aligned}
& R T W_{t}=u_{t-1} \times\left(\phi_{10}+\sum_{j=1}^{2}\left(\phi_{1 j} R T W_{t-j}+\phi_{2 j} R K O R E A_{t-j}\right)+a_{1, t}\right)
\end{aligned}
$$

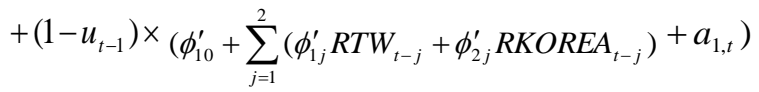

$$
\begin{aligned}
& \text { RKOREA }_{t}=u_{t-1} \times\left(\varphi_{10}+\sum_{j=1}^{2}\left(\varphi_{1 j} R T W_{t-j}+\varphi_{2 j} \text { RKOREA }_{t-j}\right)+a_{2, t}\right) \\
& +\left(1-u_{t-1}\right) \times\left(\varphi_{10}^{\prime}+\sum_{j=1}^{2}\left(\varphi_{1 j}^{\prime} R T W_{t-j}+\varphi_{2 j}^{\prime} R_{R O R E A_{t-j}}\right)+a_{2, t}\right) \\
& h_{11, t}=u_{t-1}\left(\alpha_{10}+\alpha_{11} a_{1, t-1}^{2}+\beta_{11} h_{11, t-1}+\eta_{1} a_{2, t-1}^{2}\right) \\
& +\left(1-u_{t-1}\right)\left(\alpha_{10}^{\prime}+\alpha_{11}^{\prime} a_{1, t-1}^{2}+\beta_{11}^{\prime} h_{11, t-1}+\eta_{1}^{\prime} a_{2, t-1}^{2}\right), \\
& h_{22, t}=u_{t-1}\left(\alpha_{20}+\alpha_{21} a_{2, t-1}^{2}+\beta_{21} h_{22, t-1}+\eta_{2} a_{1, t-1}^{2}\right) \\
& +\left(1-u_{t-1}\right)\left(\alpha_{20}^{\prime}+\alpha_{21}^{\prime} a_{2, t-1}^{2}+\beta_{21}^{\prime} h_{22, t-1}+\eta_{2}^{\prime} a_{1, t-1}^{2}\right), \\
& h_{12, t}=\rho_{t} \sqrt{h_{11, t}} \sqrt{h_{22, t}} \text {, } \\
& \rho_{t}=\exp \left(q_{t}\right) /\left(\exp \left(q_{t}\right)+1\right) \\
& q_{t}=\gamma_{0}+\gamma_{1} \rho_{t-1}+\gamma_{2} a_{1, t-1} a_{2, t-1} / \sqrt{h_{11, t-1} h_{22, t-1}}, \\
& u_{t}=\left\{\begin{array}{ll}
1 & \text { if } R G O P \leq 0 \\
0 & \text { if others }
\end{array},\right.
\end{aligned}
$$

the white noise of $\vec{a}_{t}^{\prime}=\left(a_{1, t}, a_{2, t}\right)$ is obey the bivariate $\mathrm{S}$ tudent's t distribution, this is, $\vec{a}_{t} \sim T_{v}\left(\overrightarrow{0},(v-2) H_{t} / v\right)$, among $\overrightarrow{0}^{\prime}=(0,0)$ and $H_{t}$ is the covariance matrix of $\vec{a}_{t}^{\prime}=\left(a_{1, t}, a_{2, t}\right)$, and $\rho_{t}$ is the dynamic conditional correlation coefficient of $a_{1, t}$ and $a_{2, t}$. $R G O P>0$ denotes the good new and $R G O P \leq 0$ denotes the bad new. The maximum likelihood algorithm method of BHHH (Berndt et. al. ${ }^{2}$ ) is used to estimate the model's unknown parameters. The programs of RATS and EVIEWS are used in this paper.

From the empirical results, we know that the Taiwan's and the Korea's stock return volatility with a factor of gold price market may be constructed on the DCC and the bivariate asymmetric IGARCH $(1,1)$ model. Its estimate result is stated in Table 6.

Table 6 Parameter Estimation of the DCC and the Bivariate Asymmetric $\operatorname{IGARCH}(1,1)$ Model

\begin{tabular}{|l|c|c|c|c|c|}
\hline Parameters & $\phi_{10}$ & $\phi_{11}$ & $\phi_{12}$ & $\phi_{21}$ & $\phi_{22}$ \\
\hline Coefficient & 0.0585 & -0.0013 & 0.0240 & 0.0446 & -0.0357 \\
\hline (p-value) & $(0.4025)$ & $(0.9858)$ & $(0.7356)$ & $(0.5052)$ & $(0.6037)$ \\
\hline Parameters & $\phi_{10}^{\prime}$ & $\phi_{11}^{\prime}$ & $\phi_{12}^{\prime}$ & $\phi_{21}^{\prime}$ & $\phi_{22}^{\prime}$ \\
\hline Coefficient & 0.1995 & 0.1215 & -0.0730 & -0.1092 & 0.0250 \\
\hline (p-value) & $(0.0010)$ & $(0.0779)$ & $(0.2482)$ & $(0.1165)$ & $(0.6929)$ \\
\hline Parameters & $\varphi_{10}$ & $\varphi_{11}$ & $\varphi_{12}$ & $\varphi_{21}$ & $\varphi_{22}$ \\
\hline Coefficient & 0.1188 & -0.0681 & 0.0477 & 0.0393 & -0.0575 \\
\hline (p-value) & $(0.0700)$ & $(0.3098)$ & $(0.4649)$ & $(0.5534)$ & $(0.4145)$ \\
\hline Parameters & $\varphi_{10}^{\prime}$ & $\varphi_{11}^{\prime}$ & $\varphi_{12}^{\prime}$ & $\varphi_{21}^{\prime}$ & $\varphi_{22}^{\prime}$ \\
\hline Coefficient & 0.1872 & 0.0727 & -0.1482 & -0.0761 & 0.1133 \\
\hline (p-value) & $(0.0015)$ & $(0.2684)$ & $(0.0130)$ & $(0.2455)$ & $(0.0842)$ \\
\hline Parameters & $\alpha_{10}$ & $\alpha_{11}$ & $\beta_{11}$ & $\eta_{1}$ & $\alpha_{10}^{\prime}$ \\
\hline Coefficient & 0.0812 & 0.1032 & 0.8865 & 0.0103 & 0.0903 \\
\hline (p-value) & $(0.2147)$ & $(0.0035)$ & $(0.0035)$ & $(0.6453)$ & $(0.1482)$ \\
\hline Parameters & $\alpha_{11}^{\prime}$ & $\beta_{11}^{\prime}$ & $\eta_{1}^{\prime}$ & $\alpha_{20}$ & $\alpha_{21}$ \\
\hline Coefficient & 0.0997 & 0.7930 & 0.1073 & 0.0247 & 0.1169 \\
\hline (p-value) & $(0.0249)$ & $(0.0249)$ & $(0.0171)$ & $(0.7246)$ & $(0.0037)$ \\
\hline Parameters & $\beta_{21}$ & $\eta_{2}$ & $\alpha_{20}^{\prime}$ & $\alpha_{21}^{\prime}$ & $\beta_{21}^{\prime}$ \\
\hline Coefficient & 0.8604 & 0.0227 & 0.1042 & 0.0926 & 0.8275 \\
\hline (p-value) & $(0.0037)$ & $(0.4009)$ & $(0.1062)$ & $(0.0077)$ & $(0.0077)$ \\
\hline Parameters & $\eta_{2}^{\prime}$ & $v$ & $\bar{\rho}_{t}$ & $\min \rho_{t}$ & $\max \rho_{t}$ \\
\hline Coefficient & 0.0699 & 5.0382 & 0.7207 & 0.5391 & 0.9234 \\
\hline (p-value) & $(0.0311)$ & $(0.0000)$ & $(0.0000)$ & & \\
\hline Parameters & $\gamma_{0}$ & $\gamma_{1}$ & $\gamma_{2}$ & & \\
\hline Coefficient & 3.8768 & -4.0226 & -0.0432 & & \\
\hline (p-value) & $(0.0001)$ & $(0.0020)$ & $(0.3350)$ & & \\
\hline
\end{tabular}

Notes: p-value $<\alpha$ denotes significance. $(\alpha=1 \%, \alpha=5 \%)$.min $\rho_{t}$ denotes the minimum $\rho_{t}$ and max $\rho_{t}$ denotes the maximum $\rho_{t}$.

Empirical result shows that, under the good news $(R G O P>0)$, the Taiwan's stock market return receives before first period's impact of the Taiwan's stock market return $\left(\phi_{11}^{\prime}=0.1215\right)$. And the Taiwan's stock market return does not receive before two period's impact of the Korea's stock market return. Under the good news, the Korea's stock market return receives before second period's impact of the Taiwan's stock market return $\left(\varphi_{12}^{\prime}=-0.1482\right)$. And the Korea's stock market return receives before second period's impact of the Korea's stock market return $\left(\varphi_{22}^{\prime}=0.1133\right)$. On the other hand, the correlation coefficient average estimation value $\left(\bar{\rho}_{t}=0.7207\right)$ of the Taiwan's and the Korea's stock return volatility is significant. This result also shows the Taiwan's and the 
Korea's stock price return's volatility are mutually synchronized influence. In additional, estimated value of the degree of freedom for the Student's t distribution is 5.0382, and is significant under the significance level of $0.01(\alpha=1 \%)$. This also demonstrates that this research data has the heavy tailed distribution.

From the Table 6, the estimated coefficients of the conditional variance equation will produce the different variation risks under the bad and good news. In Table VI, the empirical results show that the proposed model confirms the condition supposition of the IGARCH model. This result also demonstrates the DCC and the bivariate asymmeyric IGARCH $(1,1)$ model may catch the Taiwan's and the Korea's stock market return volatilities' process. Under the bad and good news, the Taiwan's and the Korea's stock markets do not have the fixed variation risk. And the gold price market affects the variation risk of the Taiwan's and Korea's stock markets. Under the good news, the error square item of Korea's stock market affects the variation risk of the Taiwan's stock market $\left(\eta_{1}^{\prime}=0.1073\right)$. The error square item of Taiwan's stock market affects the variation risk of the Korea's stock market $\left(\eta_{2}^{\prime}=0.0699\right)$. Under the bad and good news, the Taiwan's and the Korea's stock markets have the different variation risks (for example, $\beta_{11}=0.8865$ and $\beta_{21}=0.8604$ ). The empirical result also shows that the explanatory ability of the DCC and the bivariate asymmetric $\operatorname{IGARCH}(1,1)$ model is better than the traditional model of the bivariate $\operatorname{GARCH}(1,1)$.

To test the inappropriateness of the DCC and the bivariate asymmetric IGARCH $(1,1)$ model, the test method of Ljung and $\mathrm{Box}^{10}$ is used to examine autocorrelation of the standard residual error. This model does not show an autocorrelation of the standard residual error. Therefore, the DCC and the bivariate asymmetric $\operatorname{IGARCH}(1,1)$ model are more appropriate.

\section{Conclusions}

The empirical results show that the Taiwan's and the Korea's stock market return's volatility with a factor of the gold price market have an asymmetric effect, and the Taiwan's and the Korea's stock price return volatility may construct in the DCC and the bivariate asymmetric $\operatorname{IGARCH}(1,1)$ model. From the empirical result also obtains that the dynamic conditional correlation coefficient average estimation value ( $\left.\bar{\rho}_{t}=0.7207\right)$ of the Taiwan's and the Korea's stock price return volatility is positive. The gold market price volatilities truly affect the variation risk of the Taiwan's stock market. And the gold market price volatilities also truly affect the variation risk of the Korea's stock market. Under the good news, the error square item of the Taiwan's stock market affects the variation risk of the Korea's stock market. The error square item of the Korea's stock market also affects the variation risk of the Taiwan's stock market. Based on the paper of Engle ${ }^{6}$, the explanation ability of the DCC and the bivariate asymmetric $\operatorname{IGARCH}(1,1)$ is better than the traditional bivariate $\operatorname{GARCH}(1,1)$ model. In the future, we will further to study the influence of the gold market on others stock markets.

\section{References}

[1] G. Schwarz, Estimating the dimension of a model, Annals of Statistics, 6(2), pp.461-464 (1978).

[2] E.K. Berndt, B.H. Hall, R.E. Hall, and J.A. Hausman, Estimation and inference in nonlinear structural models, Annals of Economic and Social Measurement, 4, pp. 653-665 (1974).

[3] D.A. Dickey, and W.A. Fuller, Distribution of the Estimators for Autoregressive Time Series with a Unit Root, Journal of the American Statistical Association 74, pp.427-431 (1979).

[4] R.F. Engle, Autoregressive conditional heteroskedasticity with estimates of the variance of United Kingdom Inflation", Econometrica, 50, pp. 987-1007 (1982)

[5] R.F. Engle, and V.K Ng, Measuring and Testing the Impact of News on Volatility, Journal of Finance 48(5), pp.1749-1777 (1993).

[6] R.F. Engle, Dynamic conditional correlation- a simple class of multivariate GARCH models, Journal of Business and Economic Statistics, 20, pp.339-350 (2002).

[7] S. Hammoudeh, H. Li, and B. Jeon, Causality and volatility spillovers among petroleum prices of WTI, gasoline and heating oil in different locations. North, American Journal of Economics and Finance, 13(1), pp.89-114 (2003).

[8] S. Hammoudeh, S. Dibooglu, and E. Aleisa, Relationships among U.S. oil prices and oil industry equity indices, International Review of Economics and Finance, 13, pp.427-453 (2004).

[9] S. Johansen, Estimation and Hypothesis Testing of Cointegration Vector in Gaussian Vector Autoregressive Models, Econometrica 59, pp.15511580 (1991)

[10] G.M. Ljung, and G.E.P. Box, On a measure of lack of fit in time series models", Biometrika, 65, pp.297-303 (1978).

[11] R.S. Tsay, Analysis of Financial Time Series, New York: John Wiley \& Sons, Inc (2004).

[12] Y.K. Tse, and Albert K.C. Tsui, A multivariate GARCH model with time-varying correlations, Journal of Business \& Economic Statistics, 20, pp.351-362 (2002).

[13] G. Kapetanios, Y. Shin, and A. Snell, Testing for a unit root in the nonlinear STAR framework, Journal of Econometrics, 112(2), pp.359379 (2003).

[14] T. Bollerslev,, Modeling the coherence in short-run nominal exchange rates: a multivariate generalized $\mathrm{ARCH}$ model, Review of Economics and Statistics, 72, pp.498-505, (1990) 